\title{
The evolving landscape of human papillomavirus-related oropharyngeal squamous cell carcinoma at a single institution in Northern Italy
}

\author{
Carcinoma squamocellulare HPV-correlato dell'ipofaringe: \\ evoluzione epidemiologica in un singolo centro italiano
}

\author{
P. MORBINI ${ }^{1,2}$, P. ALBERIZZI ${ }^{2}$, G. FERRARIO ${ }^{2}$, G. CAPELLO ${ }^{2}$, A. DE SILVESTRI ${ }^{3}$, P. PEDRAZZOLI ${ }^{4}$, \\ C. TINELLI ${ }^{3}$, M. BENAZZO ${ }^{5}$
}

${ }^{1}$ Department of Molecular Medicine, Pathology Unit, University of Pavia, Italy; ${ }^{2}$ Pathology Unit, Foundation IRCCS Policlinico S. Matteo, Pavia, Italy; ${ }^{3}$ Clinical Epidemiology and Biometrics Unit, Foundation IRCCS Policlinico

S. Matteo, Pavia, Italy; ${ }^{4}$ Department of Oncology, Foundation IRCCS Policlinico S. Matteo, Pavia, Italy;

${ }^{5}$ Department of Otolaryngology, University of Pavia and Foundation IRCCS Policlinico S. Matteo, Italy

\section{SUMMARY}

The increasing incidence of HPV-related oropharyngeal squamous cell carcinoma (OPSCC) observed in several developed countries has not yet been documented in Italy. To investigate changes in the epidemiology of HPV-related OPSCC we reviewed the HPV status of cases evaluated at our centre in northern Italy before and after 2010. The results were correlated with patient age, sex, oropharyngeal subsite (classified as palatine tonsil, tongue base, palatine arch/palate/uvula, posterior oropharyngeal wall, and oropharynx not otherwise specified), AJCC tumour stage, risk factor exposure (smoke, alcohol), disease history (recurrence, metastasis, second tumours), outcome and survival. Positivity for p16 and HR HPV DNA was required to classify HPV-related OPSCC. HPV-related tonsillar OPSCC increased significantly after 2010, while a non-significant reduction of HPV-related extra-tonsillar OPSCC was observed. Non-keratinising morphology was strongly associated with HPV positivity. HPV16 was the most common genotype; the frequency of other high-risk genotype infections decreased after 2010. At multivariate analysis, HPV status showed a significant association with better outcome. We documented an increase of HPV-related OPSCC in our Italian population, synchronous with the increase observed in several Western countries, which in recent years reached a prevalence similar to that reported in central European countries. Our results indicate that HPV infection in head and neck oncology is relevant in Italy and needs to be considered for accurate patient stratification.

KEY WORDS: Human papillomavirus • Oropharyngeal cancer • Prevalence • Oncogenic • HPV infection

\section{RIASSUNTO}

L'incidenza dei carcinomi squamosi dell'orofaringe (OPSCC) correlati all'infezione da papillomavirus umano (HPV) risulta essere in aumento in numerosi Paesi industrializzati, ma questo dato non è ancora stata confermato in Italia. Con l'obiettivo di analizzare i mutamenti occorsi nell' epidemiologia degli OPSCC HPV-correlati sono stati rivisti e confrontati i risultati delle indagini di caratterizzazione di HPV eseguite sui casi di OPSCC diagnosticati presso un singolo centro nell'Italia settentrionale prima e dopo il 2010, correlando anche con età, sesso, sottosede anatomica (tonsilla palatina, base della lingua, pilastri palatini/palato/ugola, parete posteriore dell'orofaringe e orofaringe non ulteriormente precisata), stadiazione TNM, fattori di rischio (fumo, alcol), evoluzione (recidiva, metastasi, secondo tumore), esito, e durata della sopravvivenza. Si è osservato un significativo aumento, dopo il 2010, dei tumori tonsillari HPV-correlati, riconosciuti in base all'espressione di p16 e alla positività per DNA di genotipi ad alto rischio, in parallelo con una riduzione non significativa dei casi di tumore HPV-correlato ad origine extratonsillare. HPV16 è risultato il genotipo più comune; la frequenza delle infezioni sostenute da altri genotipi ad alto rischio ha mostrato una riduzione dopo il 2010. All'analisi multivariata, lo stato di HPV risultava associato con una miglior prognosi. Nell nostro centro abbiamo documentato un aumento dei casi di OPSCC HPV-correlato che coincide temporalmente con quanto osservato in numerosi paesi occidentali; la prevalenza registrata è simile a quella riportata in altre nazioni del centro Europa. I risultati indicano che l'infezione da HPV ha un ruolo in oncologia otorinolaringoiatrica nel nostro paese, e deve essere tenuta in considerazione per un corretto inquadramento clinico dei pazienti. 


\section{Introduction}

In 2007, the World Health Organization (WHO) recognised that high risk human papillomavirus (HR HPV) genotypes are responsible for the development of a subset of oropharyngeal (OP) squamous cell carcinomas (SCC), and of a smaller proportion of oral carcinomas ${ }^{1}$. This observation, associated with the evidence of sexual transmission of HPV oropharyngeal infection, younger patient age, different exposure to conventional risk factors ${ }^{2}$, and in particular a more favourable prognosis ${ }^{3}$, has stimulated extensive studies aimed at better defining the epidemiology of HPV-associated tumours.

At the same time, the worldwide analysis of cancer registry data ${ }^{4}$ has provided evidence of increasing incidence rates of oropharyngeal cancer in several economically developed countries, especially among men $<60$ years old, despite the concomitant declining incidence of tobaccorelated oral cavity SCC. This trend, particularly relevant in North America and northern European countries, has strongly suggested a change in risk factors, supported by a series of individual studies and meta-analyses that documented a sharp increase in the prevalence of OPSCC attributable to oncogenic HPV infection over the last decades ${ }^{5}$. The most recent worldwide estimates for HPV-attributable OPSCC amount to $18-28 \%{ }^{5}$, but a recent large international study documented high variability among geographical areas ${ }^{6}$. In particular, the HPV-attributable fraction was lowest in southern Europe (7.6\%) than in any other considered area (South America, central-eastern Europe, northern Europe, eastern Asia, central America, western Europe) in samples collected over a long time interval (1990-2012). Moreover, only part of the published single-population studies employed methods that discriminate oncogenic from incidental HPV infection, further impairing data comparison. Similarly, the projections on the increase of HPV-related OPSCC in the United States population over the next decade can not be reliably applied to other populations ${ }^{7}$. OPSCC HPV status is expected to impact patient treatment choices: retrospective and prospective data show that HPV-related OPSCC is associated with better prognosis, in particular in patients with locoregionally advanced diseases, and several de-intensified treatment trials are currently undergoing evaluation ${ }^{89}$.

At variance with other Western countries, national cancer registries in Italy are lacking, and the coverage by local registries is heterogeneous in terms of geographical distribution and recorded tumour types (http://www. registri-tumori.it/cms/en). Neither nationwide data on oral and oropharyngeal SCC prevalence nor data on the prevalence of HPV infection in the oral cavity and in oral and oropharyngeal cancers are available. According to the Cancer Incidence in Five Continents Registry, a moderate parallel reduction of both oral and oropharyngeal cancer incidence has occurred in Italy over the last ${ }^{3}$ decades ${ }^{4}$. A recent meta-analysis reporting OPSCC prevalence and HPV involvement in 29 countries suggested that HPVrelated OPSCC in southern Europe are less frequent than in northern Europe and America ${ }^{10}$. Small single-centre studies suggest a lower but nonetheless increasing prevalence of HPV-related OPSCC: two studies published by the same institution in Milan with a 6-year interval reported a prevalence increasing from $17 \%^{11}$ to $50 \%{ }^{12}$; furthermore, two recent studies reported that HPV infection was responsible of $32 \%$ and $39.8 \%$ of in two consecutive series collected in different Roman institutions between 2009-2011 and 2010-2014 ${ }^{13} 14$.

The head and neck tumour board at the Foundation IRCCS Policlinico San Matteo and University of Pavia has been investigating HPV infection in retrospective and prospective tumour series since $2003^{15}{ }^{16}$. In the present study, we reviewed all previously collected data in order to assess changes occurred in the epidemiology of OPSCC with respect to HPV infection in the population referring to our centre over the last two decades.

\section{Materials and methods}

\section{Patient series and data collection}

We retrospectively analysed the charts of the Pathology Unit to collect SCC cases occurring at any oropharyngeal subsite since 1992, when the digital archive of the Unit was started. For each patient, the following data were retrieved, when available: age, gender, anatomical tumour site (classified as palatine tonsil, tongue base, palatine arch/palate/uvula, posterior oropharyngeal wall and oropharynx not otherwise specified), tumour stage according to the American Joint Committee on Cancer (AJCC) staging system ${ }^{17}$, risk factor exposure (smoke, alcohol), disease history (recurrence, metastasis, second tumours in the area), outcome, disease-free survival, overall survival, and HPV testing methods and results. The histological slides of all cases tested for HPV were also reviewed to record the presence of tumour cell keratinisation. HPV analysis was performed in compliance with relevant laws and institutional guidelines, and in accordance with the ethical standards of the Declaration of Helsinki. Informed consent was obtained from all patients at the time of testing. The study protocols were approved by the Institutional Ethical Review Board. 


\section{HPV testing}

To define OPSCC HPV status we applied a validated diagnostic algorithm ${ }^{16}$, slightly modified with respect to those previously published ${ }^{18}{ }^{19}$, which includes p16 immunostaining, HR HPV DNA in situ hybridisation (ISH) and HPV genotyping. Positivity for p16 and HR HPV DNA (by ISH and/or PCR) was required to classify HPV-related OPSCC. All tests were performed according to recently described protocols ${ }^{16}$. Cases that at chart review had ambiguous results or only partial testing were completed according to the algorithm employing the most recent test version. In particular, cases with positive p16 immunostaining that resulted negative for HR-HPV or positive for non-HPV16 HR genotypes underwent specific amplification of the E6 gene of HPV16 ${ }^{16}$.

For immunohistochemical detection of p16, the CINtec ${ }^{\circledR}$ Histology Kit (Roche MTM Laboratories AG, Heidelberg, Germany) was used according to the manufacturer's instructions on a Ventana BenchmarkTX automated stainer (Ventana Medical Systems Inc., Tucson, AZ). Samples of high grade cervical intraepithelial lesions were used as positive controls. Strong and diffuse nuclear and cytoplasmic staining in $>70 \%$ of tumour cells was considered as positive according to previous studies ${ }^{314}$. HPV DNA ISH was performed with the INFORM-HPV III family 16 probe using the ISH I View Blue Plus Detection Kit according to the manufacturer's instructions, on a Ventana BenchmarkTX automated stainer. Any definitive (diffuse or dot-like) nuclear staining in tumour cells was considered positive. Cases were classified in a binary manner as either positive or negative. DNA extraction and HPV typing were performed according to previously reported protocols, using the INNO-LiPA HPV genotyping assay version Extra and Extra II (Fujirebio Europe, Ghent, Belgium). The Extra version of the assay allows the simultaneous and separate detection of 18 HR $(16,18,26,31,33,35,39,45,51,52,53,56,58,59$, 66, 68, 73 and 82), 7 low risk (LR) (6, 11, 40, 43, 44, 54 and 70), and 2 unclassified HPV types (69/71 and 74). Hybridisation patterns were analysed with the specific scanner Line reader and Analysis Software (LiRAS) for LiPA HPV and the results were confirmed by two independent readers. For HPV16 E6 PCR the DNA was amplified using a primer pair (3': CCATGCATGATTACAGCTGG; 5': GAACAGCAATACAACAAACCG) that amplifies a 201bp fragment within the E6 gene of HPV $16^{16}$. Amplification parameters were $94^{\circ} \mathrm{C} 10^{\prime}$, followed by $95^{\circ} \mathrm{C} 30^{\prime \prime}, 60^{\circ} \mathrm{C} 15^{\prime}$, $72^{\circ} \mathrm{C} 30^{\prime \prime}$ for 35 cycles, and $72^{\circ} \mathrm{C} 5^{\prime}$ final extension. Amplified products were analysed by electrophoresis on $2 \%$ agarose gel. SiHA cells containing a known number of HPV16 DNA copies and blank reagents were used as positive and negative controls in each PCR run, respectively.

\section{Statistical analysis}

The Shapiro-Wilk test was used to test the normal distribution of quantitative variables: if quantitative variables were normally distributed, the mean value and standard deviation (SD) were reported; otherwise results were expressed as median and interquartile range (IQR). Qualitative variables were summarised as counts and percentages. Comparisons among categorical data were analysed by chi square or Fisher's exact test, as appropriate. Univariate and multivariate (including factors significantly associated with survival at univariate analysis) Cox models were fitted to study overall survival (OS) and disease-free survival (DFS); the results were expressed as hazard ratio (HR) with their $95 \%$ confidence interval (CI). As a sensitivity analysis a competing risk model was also fitted. To avoid bias due to missing loco-regional recurrence (LRR) data, a multiple imputation model for missing data was fitted taking into account gender, age, survival, HPV, T stage, M1, surgical treatment, keratinising tumour phenotype. A total of 10 datasets were created and used as a sensitivity analysis. All tests are two-sided, a p-value $<0.05$ was considered as significant. All analyses were performed with STATa 14.1 (StataCorps, College Station, USA).

\section{Results}

\section{Approach to HPV testing}

For the study purposes, OPSCC patients were divided in 2 groups according to the time of diagnosis, before and after 2010. There were 175 newly diagnosed OPSCC before 2010, and 81 between 2010 and November 2015. HPV status had been determined in 124 patients, $53(30.2 \%)$ before 2010 and $71(87.6 \%)$ after. Reasons for HPV testing of OPSCC diagnosed before 2010 were patient enrolment in study protocols ${ }^{15}$, or the occurrence of a new oropharyngeal primary tumour after 2010; since 2010, the diagnostic evaluation of OPSCC approved by the institutional tumour board included the assessment of HPV status in all new cases. Referrals from other centres that provided HPV testing and/or patients with advanced disease with no therapeutic indication account for the untested cases after 2010. Age, sex, stage and risk factor distribution in tested and untested patient groups is detailed in Table I. The patient first-line treatment included surgery, chemotherapy and radiotherapy with different modalities according to the evolving standards of care over the period included in the study. The two populations significantly differed for a higher proportion of moderate/heavy drinkers $(p=0.033)$ and tumour recurrences $(p=0.03)$ in the untested population after 2010. In this group, we also observed a significantly $(\mathrm{p}<0.000)$ shorter DFS, consequent 
to the exclusion of the most advanced cases from HPV testing. The anatomical distribution of tumours was similar in tested and untested cases (Table II); before 2010, tonsillar SCC were tested more frequently $(\mathrm{p}=0.02)$ than tumours occurring at other oropharyngeal subsites, while after 2010 no selection took place based on tumour site within the oropharynx.

\section{HPV-associated OPSCC epidemiology}

Evidence of transcriptionally active HR HPV infection was found in 47 cases (37.9\%). HPV-related OPSCC became more frequent after $2010(32,45 \%$ vs $15,28.3 \%)$, but the difference did not reach significance $(\mathrm{p}=0.06)$. Comparing tumours involving at least one tonsillar subsite (palatine tonsil and base of tongue) with those only involving extra-tonsillar subsites, respectively, $44.7 \%$ and $14.2 \%$ were positive $(\mathrm{p}=0.003)$. In tonsillar SCC, the proportion of HPV-related cases increased significantly after 2010 (31.7\% before, $54.5 \%$ after, $\mathrm{p}=0.03)$, while a modest non-significant reduction of HPV-related extra-tonsillar tumours was observed (16.6\% vs $12.5 \%)$. Considering the difficulty of a precise clinical definition of tumour origin, especially in advanced cases, the mor- phological characters of tumours were also taken into account. Non-keratinising tumour phenotype was strongly associated with HPV positive status in the overall series ( $p<0,0001$ ): $58.8 \%$ of non-keratinising tumours were HPV-positive, compared to $12.5 \%$ of those showing cell maturation and keratinisation. Among non-keratinising tumours, 50\% were HPV-related before 2010, and 63.6\% after (ns), vs $10.6 \%$ and $14.8 \%$ of keratinising tumours (ns). Previous palatine tonsillectomy was reported by 12 patients. Five had an HPV-associated OPSCC, involving in all cases the lingual tonsil and showing the non-keratinising phenotype.

\section{HPV infection distribution and features}

Overall, 87 (70.1\%) cases were positive for HPV DNA. The proportion of DNA-positive cases did not significantly increase over time $(69.8 \%$ before 2010 and $71.8 \%$ after). HR HPV DNA was found in $56.3 \%$ of cases before 2010, and $60.3 \%$ after (ns). Beside OPSCC with evidence of oncogenic viral activity (i.e. p16 expression), HR HPV DNA was observed in 25 of the 77 (32.4\%) p16negative tumours, suggesting passenger infection. The proportion of HPV-unrelated tumours hosting passenger

Table I. Comparison of clinical features of HPV-investigated and not investigated OPSCC patient groups.

\begin{tabular}{|c|c|c|c|c|c|c|c|c|c|c|c|c|c|}
\hline \multirow[t]{2}{*}{ Group } & \multirow{2}{*}{$\begin{array}{l}\text { Sex } \\
M / F\end{array}$} & \multirow{2}{*}{$\begin{array}{c}\text { Age } \\
\text { (years) }\end{array}$} & \multicolumn{4}{|c|}{ Stage $^{a}$} & \multirow{2}{*}{$\begin{array}{c}\text { Surgery } \\
\text { T/N }\end{array}$} & \multirow{2}{*}{$\begin{array}{c}\text { Smoke }^{\mathrm{a}} \\
\mathrm{Y} / \mathrm{N}^{\mathrm{b}}\end{array}$} & \multirow{2}{*}{$\begin{array}{c}\text { Alcohol }^{\mathrm{a}} \\
\mathrm{Y} / \mathrm{N}^{\mathrm{c}}\end{array}$} & \multicolumn{2}{|c|}{ Recurrence $^{a}$} & \multirow{2}{*}{$\begin{array}{l}\mathrm{DSD}^{\mathrm{a}} \\
\mathrm{Y} / \mathrm{N}\end{array}$} & \multirow{2}{*}{$\begin{array}{c}\text { FUa }^{a} \\
\text { (months) }\end{array}$} \\
\hline & & & $0-1$ & 2 & 3 & 4 & & & & $\mathrm{Y} / \mathrm{N}$ & DFS (months) & & \\
\hline $1992-2010$ & $142 / 33$ & $59.5 \pm 9.6$ & 9 & 25 & 37 & 69 & 49/45 & $24 / 27$ & $32 / 10$ & $63 / 18$ & $57.8 \pm 50.4$ & $49 / 91$ & $69.7 \pm 54.1$ \\
\hline Tested & $45 / 8$ & $59.9 \pm 10.2$ & 4 & 13 & 15 & 21 & $20 / 20$ & $14 / 15$ & $12 / 7$ & $22 / 3$ & $60.1 \pm 52.7$ & $24 / 24$ & $74.8 \pm 58.1$ \\
\hline Untested & $97 / 25$ & $58.1 \pm 10.72$ & 5 & 12 & 22 & 48 & $29 / 25$ & $10 / 12$ & $20 / 3$ & $41 / 15$ & $54.2 \pm 45.2$ & $25 / 67$ & $60 \pm 44.3$ \\
\hline p & Ns & Ns & Ns & Ns & Ns & Ns & Ns & Ns & Ns & Ns & & & \\
\hline 2011-2015 & $65 / 16$ & $63.5 \pm 10.4$ & 6 & 6 & 19 & 48 & $32 / 33$ & $48 / 22$ & $36 / 25$ & $15 / 44$ & $23.9 \pm 14.4$ & $17 / 60$ & $22.0 \pm 14.4$ \\
\hline Tested & $56 / 15$ & $63.8 \pm 10.3$ & 5 & 6 & 16 & 43 & $25 / 25$ & $42 / 21$ & $29 / 25$ & $11 / 42$ & $25.2 \pm 14.6$ & $17 / 53$ & $22.1 \pm 14.7$ \\
\hline Untested & $9 / 1$ & $61.5 \pm 11.7$ & 1 & 0 & 3 & 5 & $7 / 8$ & $6 / 1$ & $7 / 0$ & $4 / 2$ & $12.5 \pm 4.5$ & $0 / 7$ & $20.7 \pm 12.6$ \\
\hline$p$ & Ns & Ns & Ns & Ns & Ns & 0.033 & 0.031 & 0.000 & Ns & Ns & & & \\
\hline
\end{tabular}

a: data not available for the complete case series; b: never smoker or former smoker (any number) quitting more than 5 years before cancer diagnosis; c: clinical or laboratory evidence of alcoholism; M: male; F: female; SD: standard deviation; Y: yes; N: no; DFS: disease-free survival; DSD: disease-specific death; FU: follow-up; Ns: not significant.

Table II. Comparison of oropharyngeal subsite involvement in tested and untested OPSCC patients.

\begin{tabular}{|c|c|c|c|c|c|}
\hline Group & Palatine tonsila & Base of tongue ${ }^{a}$ & Palatine $\operatorname{arch}^{\mathrm{a}}$ & Posterior walla & NOS \\
\hline $1992-2010$ & 74 & 74 & 37 & 2 & 8 \\
\hline Tested - n (\%) & 30 (40.5) & $13(17.5)$ & $11(29.7)$ & $2(100)$ & $4(50)$ \\
\hline$p^{b}$ & 0.02 & Ns & Ns & Ns & Ns \\
\hline 2010-2015 & 30 & 45 & 27 & 1 & 4 \\
\hline Tested - n (\%) & 29 (96.6) & 37 (82.2) & 26 (96.2) & $1(100)$ & $3(75)$ \\
\hline$p^{b}$ & Ns & Ns & Ns & Ns & Ns \\
\hline Total & 104 & 109 & 64 & 3 & 12 \\
\hline Tested - n (\%) & $59(56.7)$ & $50(45.8)$ & 37 (57.8) & $3(100)$ & $7(18.5)$ \\
\hline$p^{b}$ & 0.03 & Ns & Ns & Ns & Ns \\
\hline
\end{tabular}

a: more than one subsite could be involved in the same patient; b: compared with all other sites combined; NoS: not otherwise specified; Ns: not significant. 
HR HPV DNA was $30.1 \%$ before 2010 and $11.2 \%$ after $(\mathrm{p}=0.01)$. Analysing the correlation between HPV infection and anatomical subsite, HPV infection rate was not different in tonsillar and extratonsillar tumours (71.1 and $70 \%$ ), however, HR genotypes, independently of their oncogenic activity, were significantly more common at tonsillar (63.9 vs $25 \%, \mathrm{p}=0.002)$, and LR at extratonsillar sites ( 19.5 vs $45 \%, \mathrm{p}=0.01)$; furthermore, the nonkeratinising phenotype was significantly associated with any (82.3 vs $51.1 \%, \mathrm{p}=0.002)$ and HR HPV infection (70.5 vs $41 \%, p=0.001$ ), while no difference was observed for LR HPV infections (19.1 vs $25 \%$ ).

HPV16 was the most common genotype, being present in 55 cases (63.2\% of the 87 cases positive for HPV DNA, and $77.4 \%$ of the 71 cases positive for HR genotypes) (Table III). It was identified in $85 \%$ of 47 oncogenic and in $62.5 \%$ of 24 passenger HR HPV infections. The proportion of HR infections sustained by HPV16 was significantly higher after 2010 (36 of 40 HR HPV DNA-positive cases, 90\%), while in the previous period 12 of 31 (38.7\%) HR HPV DNA-positive cases were negative for HPV16 and showed different single or multiple HR genotypes $(p=0.008)$. The proportion of oncogenic and passenger HR infections due to HPV16 was not significantly different before and after 2010. Of the 7 oncogenic infections negative for HPV16, before 2010 one was positive for HPV52, one for HPV31 and 2 for uncharacterised genotypes (considered to be HR for positive p16 and ISH results); after 2010, one was positive for HPV35, one for HPV51 and 52, and the last case was positive for uncharacterised genotypes. Coinfections with more than one HR genotype were observed in 7 oncogenic and 3 passenger infections before 2010, and in 6 oncogenic infections after. HPV52 was present in 11 cases, HPV31, 35 and 56 in 4 cases each, HPV51 in 3, HPV45 in 2, and HPV18, 33, 39 and 59 in 1 case each. Coinfection with low and intermediate risk genotypes were also observed. The overall number of HR non-HPV16 individual infections was 25 in 17 patients before 2010 (one case confected by 5 HR genotypes and 3 cases by 3 ), and 11 in 8 patients after ( 2 cases coinfected by 2 genotypes, beside HPV16). Non HPV16 HR genotypes, either isolated or associated with HPV16, were significantly more frequent before 2010 than after $(\mathrm{p}=0.002)$, and in passenger than in oncogenic infections ( 15 of 24 vs 11 of $47, p=0.001$ ). The number of passenger infections involving non-16 HR genotypes was significantly higher before 2010 than after $(87.5 \%$, vs $12,5, \mathrm{p}<0.001)$, while $36.3 \%$ and $21.8 \%$ of oncogenic infections had non-16 genotypes in the two periods (ns), respectively.

\section{Clinical and prognostic correlations}

Age, sex, proportion of cases treated with surgery and AJCC stage distribution was similar in HPV-related and unrelated tumours in the overall series and two time periods. Tobacco smoke and alcohol consumption were significantly less frequent in HPV-related cases ( $p=0.002$ and 0.007 , respectively) in the overall series (Table IV). Complete response to therapy was more frequent in HPVpositive patients in the whole series $(\mathrm{p}=0.001)$ (Table V) and in the most recent cohort $(\mathrm{p}=0.002)$. In patients with complete response, LRR was significantly less frequent in HPV-related cases in both cohorts, while distant metastases were rare and not significantly different; DFS was significantly longer in HPV-positive patients only in cases diagnosed in the 2001-2010 period $(p=0.03)$. Diseasespecific deaths were significantly more frequent in HPVnegative patients in both cohorts $(\mathrm{p}=0.001$ and 0.01$)$. Cox proportional hazard analysis showed that OS was significantly associated with LRR $(\mathrm{p}<0.001)$, T stage $\geq 2$ $(\mathrm{p}=0.004), \mathrm{M} 1(\mathrm{p}<0.001)$, HPV status $(\mathrm{p}<0.001)$ and keratinising tumour phenotype $(p=0.02)$. At multi-

Table III. HR HPV genotype distribution.

\begin{tabular}{|c|c|c|c|c|}
\hline Genotype distribution & HPV DNA+ $(n=87)$ & HR HPV DNA+ $(n=71)$ & Oncogenic infection ( $n=47)$ & Passenger infection $(n=24)$ \\
\hline HPV $16+(n=55)$ & $63.2 \%$ & $77.4 \%$ & $85.1 \%(40)$ & $62.5 \%(15)$ \\
\hline Before $2010(n=19)$ & $51.3 \%(19 / 37)$ & $61.2 \%(19 / 31)$ & $73.3 \%(11 / 15)$ & $50 \%(8 / 16)$ \\
\hline After $2010(n=36)$ & $72 \%(36 / 50)$ & $90 \%(36 / 40)$ & $90.6 \%(29 / 32)$ & $87.5 \%(7 / 8)$ \\
\hline $\mathrm{p}$ & Ns & 0.008 & Ns & Ns \\
\hline HR non-16 infections $(n=26)$ & $29.8 \%$ & $36.6 \%$ & $23.4 \%(11)$ & $62.5 \%(15)$ \\
\hline Before $2010(n=18)$ & $48.6 \%(18 / 37)$ & $58 \%(18 / 31)$ & $36.3 \%(4 / 15)$ & $87.5 \%(14 / 16)$ \\
\hline After $2010(\mathrm{n}=8)$ & $16 \%(8 / 50)$ & $20 \%(8 / 40)$ & $21.8 \%(7 / 32)$ & $12.5 \%(1 / 8)$ \\
\hline$p$ & 0.002 & 0.002 & ns & $<0.001$ \\
\hline HR coinfections $(n=16)$ & $18.3 \%$ & $22.5 \%$ & $19.1 \%(9)$ & $29.1 \%(7)$ \\
\hline Before $2010(n=10)$ & $27 \%(10 / 37)$ & $32.2 \%(10 / 31)$ & $20 \%(3 / 15)$ & $66.6 \%(7 / 16)$ \\
\hline After $2010(n=6)$ & $12 \%(6 / 50)$ & $15 \%(6 / 40)$ & $18.7 \%(6 / 32)$ & $0(0 / 8)$ \\
\hline$p$ & Ns & Ns & Ns & 0.05 \\
\hline
\end{tabular}

Ns: not significant. 
variate analysis, HPV status ( $\mathrm{p}=0.001)$, together with $\mathrm{T}$ stage $\geq 2(\mathrm{p}=0.009)$ and M1 $(\mathrm{p}=0.001)$, showed a significant association with OS. The sensitivity analysis on 10 imputed datasets showed similar results: HPV status (HR: $0.37,95 \% \mathrm{CI}: 0.16-0.87, \mathrm{p}=0.022$ ) was significantly associated with mortality reduction, LRR and M1 with an increase (HR: 2.94, 95\% CI: 1.25-6.96, $\mathrm{p}=0.015$ and HR: $4.39,95 \%$ CI: $1.55-12.30, \mathrm{p}=0.005$ respectively). Considering the 9 deaths for other causes as a competing risk, HPV, M1 and LRR were still associated with mortality in the same way. DFS was associated with HPV status $(\mathrm{p}=0.001)$, smoking $(\mathrm{p}=0.04)$ and keratinising tumour phenotype $(\mathrm{p}=0.01)$, but only HPV status remained significant at multivariate analysis $(\mathrm{p}=0.01)$ (Fig. 1). The sensitivity analysis on 10 imputed datasets showed similar results: HPV (HR: 0.17, 95\% CI: 0.06-0.46, p < 0.001) was significantly associated with DFS.

\section{Discussion}

Several studies and meta-analyses have documented the increase of HPV-related OPSCC incidence over the last decades; Finland, United Kingdom, United States and Sweden are the most affected countries ${ }^{10}$. Our experience, although limited to a single institution in Northern Italy, similarly showed an increase in the proportion of OPSCC that could be attributed to HPV infection from $28.3 \%$ in the period $1992-2010$, to $45 \%$ in $2011-2015$. To our knowledge, this is the first report of an increase in HPV-related OPSCC case number in an Italian population over the same time interval as the increase observed in other Western countries. Recent single-centre retrospective studies from central European countries with low-to- intermediate prevalence of HPV-related OPSCC reported comparable rates of HPV-related OPSCC (40-50\%) in the most recent cohorts, with a similar increasing trend 2021. HPV-related OPSCCs rates in our series, on the other hand, are higher than those registered in other southern European countries ${ }^{6}$, and provide evidence that the role of HPV infection in head and neck oncology is relevant in Italy and needs to be considered for accurate patient stratification.

Thanks to a better definition of the criteria used to classify HPV-associated tumours ${ }^{22}$, emerging evidence in comparative studies shows that the geographic distribution of OPSCC and of their HPV attributable fraction, as well as the prevalence of non-oncogenic HPV infections, are highly heterogeneous ${ }^{6}{ }^{10}$. The impact of different tobacco and alcohol exposure has been proposed as a causative factor, although 10-30\% of HPV-related OPSCC occur in heavy smokers and/or drinkers ${ }^{23}$, as was the case in our cohort. As far as Italy is concerned, previous single-centre reports, including ours, suggest an higher prevalence in northern (40-50\%) than in central and northeastern Italy $(29-40 \%)^{11-1624}$. Differences in HPV-related OPSCC prevalence within a single country have been reported elsewhere ${ }^{25}$, and, although heterogeneous testing algorithms are powerful confounders, it is not unexpected that the geographical and ethnic complexity of the Italian population ${ }^{26}$ be reflected in a highly heterogeneous distribution of HPV infection and HPV-related cancers.

The cohort of HPV-related OPSCC in our series shared only some of the clinical features that have been associated with this subgroup of tumours. Patients with HPV-related OPSCC were more likely than those with HPV-unrelated cancers to be never or former smokers and non-drinkers,

Table IV. Comparison of clinical features and risk factor exposure in HPV-related and unrelated OPSCC patients.

\begin{tabular}{|c|c|c|c|c|c|c|c|c|c|}
\hline \multirow[t]{2}{*}{ Group } & \multirow{2}{*}{$\begin{array}{l}\text { Sex } \\
M / F\end{array}$} & \multirow{2}{*}{$\begin{array}{l}\text { Age (years) } \\
\text { Mean } \pm \text { SD }\end{array}$} & \multicolumn{4}{|c|}{ Stage $^{a}$} & \multirow{2}{*}{$\begin{array}{c}\text { Surgery } \\
\mathrm{T} / \mathrm{N}\end{array}$} & \multirow{2}{*}{$\begin{array}{c}\text { Smoke }^{\mathrm{a}} \\
\mathrm{Y} / \mathrm{N}^{\mathrm{b}}\end{array}$} & \multirow{2}{*}{$\begin{array}{c}\text { Alcohol }^{\mathrm{a}} \\
\mathrm{Y} / \mathrm{N}\end{array}$} \\
\hline & & & $0-1$ & $\mathrm{~T} / \mathrm{N}$ & 3 & 4 & & & \\
\hline $1992-2010$ & $45 / 8$ & $58.1 \pm 10.7$ & 4 & 13 & 15 & 21 & $20 / 18$ & $28 / 6$ & 23/12 \\
\hline $\mathrm{HPV}+$ & $10 / 5$ & $56.7 \pm 10.7$ & 2 & 3 & 4 & 6 & $8 / 6$ & $4 / 4$ & $5 / 3$ \\
\hline HPV - & $35 / 3$ & $58.6 \pm 10.8$ & 2 & 10 & 11 & 15 & $12 / 12$ & $24 / 2$ & $18 / 9$ \\
\hline $\mathrm{p}$ & 0.03 & Ns & Ns & & & & Ns & 0.01 & Ns \\
\hline 2010-2015 & $56 / 15$ & $63.8 \pm 10$ & 6 & 6 & 16 & 43 & $22 / 25$ & $41 / 21$ & $29 / 25$ \\
\hline $\mathrm{HPV}+$ & $27 / 5$ & $63.7 \pm 10$ & 1 & 3 & 8 & 20 & $11 / 14$ & $15 / 13$ & $8 / 17$ \\
\hline HPV - & $29 / 10$ & $63.9 \pm 10$ & 5 & 3 & 8 & 23 & $10 / 11$ & $26 / 8$ & $21 / 8$ \\
\hline$p$ & Ns & Ns & Ns & & & & Ns & 0.06 & 0.006 \\
\hline Total & $101 / 23$ & $61.4 \pm 10.8$ & 10 & 19 & 31 & 63 & $44 / 43$ & $69 / 27$ & $52 / 37$ \\
\hline $\mathrm{HPV}+$ & $37 / 10$ & $61.5 \pm 11.1$ & 3 & 6 & 12 & 25 & $19 / 20$ & $19 / 17$ & $13 / 20$ \\
\hline HPV - & $64 / 13$ & $61.3 \pm 10.6$ & 7 & 13 & 19 & 38 & $22 / 23$ & $50 / 10$ & $39 / 17$ \\
\hline $\mathrm{p}$ & Ns & Ns & Ns & & & & Ns & 0.002 & 0.007 \\
\hline
\end{tabular}

a: data not available for the complete case series; b: never smoker or former smoker quitting more than 5 years before cancer diagnosis; M: male; F: female; SD: standard deviation; Y: yes; N: no; Ns: not significant. 
Table V. Comparison of outcomes in HPV-related and unrelated OPSCC patients.

\begin{tabular}{|c|c|c|c|c|c|}
\hline Group & $\mathrm{CR}^{\mathrm{a}}$ & $\mathrm{LRR}^{\mathrm{a}}$ & $\mathrm{DR}^{\mathrm{a}}$ & DFS $^{a}$ & $\mathrm{DSD}^{\mathrm{a}}$ \\
\hline & $\mathrm{Y} / \mathrm{N}$ & $\mathrm{Y} / \mathrm{N}$ & $\mathrm{Y} / \mathrm{N}$ & Median (IQR) & $\mathrm{Y} / \mathrm{N}$ \\
\hline $1992-2010$ & $40 / 9$ & $19 / 21$ & $5 / 35$ & $34(12-65)$ & $25 / 24$ \\
\hline $\mathrm{HPV}+$ & $14 / 1$ & $2 / 12$ & $0 / 14$ & $65.5(60-90)$ & $2 / 13$ \\
\hline HPV - & $26 / 8$ & $17 / 9$ & $5 / 21$ & $24(8-60)$ & $23 / 11$ \\
\hline$p$ & Ns & 0.003 & Ns & 0.001 & 0.001 \\
\hline OR $(95 \% \mathrm{Cl})$ & $4.3(0.4-101)$ & $0.08(0.01-0.5)$ & $0(0-2.1)$ & & $0.07(0.009-0.4)$ \\
\hline 2010-2015 & $54 / 17$ & $9 / 45$ & $2 / 52$ & 17 (8-36) & $17 / 53$ \\
\hline $\mathrm{HPV}+$ & $30 / 2$ & $2 / 28$ & $2 / 28$ & $21.5(12-38)$ & $3 / 29$ \\
\hline HPV - & $24 / 15$ & $7 / 17$ & $0 / 24$ & 15 (7-27) & $14 / 24$ \\
\hline$p$ & 0.002 & 0.06 & Ns & Ns & 0.01 \\
\hline OR $(95 \%$ Cl) & $9.3(1.7-66)$ & $0.17(0.2-1.08)$ & & & $0.17(0.03-0.7)$ \\
\hline Total & $94 / 26$ & 28/66 & $7 / 96$ & $22(10-42.5)$ & $42 / 77$ \\
\hline $\mathrm{HPV}+$ & $44 / 3$ & $4 / 40$ & $2 / 41$ & $30.5(13-54)$ & $5 / 42$ \\
\hline HPV - & $50 / 23$ & $24 / 26$ & $5 / 45$ & $16(8-42)$ & $37 / 35$ \\
\hline$p$ & 0.001 & $<0.001$ & Ns & 0.018 & $<0.001$ \\
\hline OR $(95 \% \mathrm{Cl})$ & $6.7(1.7-30.4)$ & $0,1(0.02-0.3)$ & $0.4(0.05-2.7)$ & & $0.11(0.03-0.3)$ \\
\hline
\end{tabular}

CR: complete response; LRR: loco-regional recurrence; DR: distant recurrence; DFS: disease-free survival; DSD: disease-specific death; Y: yes; N: no; IQR: interquartile range; Ns: not significant; OR: odds ratio; Cl: confidence interval; a: data available only for subsets of cases.

although over half were current smokers. Age distribution was the same in the two groups. This observation can be explained with the persistently high prevalence of active smokers in our population even among young people, although sexual habits could also have an influence. AJCC stage distribution did not differ in HPV-related and unrelated OPSCC. Despite that, HPV status was strongly associated with complete response to therapy and reduced LRR and DSD risk, and was a strong predictor of both DFS and OS, in accordance with previous reports ${ }^{4}$. Prognosis was also influenced by $\mathrm{T}$ but not $\mathrm{N}$ stage. Recently, the $8^{\text {th }}$ edition of the AJCC classification updated $\mathrm{N}$ status in HPV-related OPSCC, reflecting the common observation that the previous classification did not accurately reflect prognosis in HPV-related OPSCC ${ }^{27}$.

Evidence suggests that HPV-associated OPSCC develop as a consequence of HPV infection of tonsillar epithelium ${ }^{28}$, but the diagnostic and predictive utility of this topographic association is not clear yet. Our experience indicates that a precise identification of the anatomical origin of the tumour within the oropharynx can be difficult at imaging and clinical evaluation, in particular for tumours that involve more than one oropharyngeal subsite, and that a non-keratinising tumour phenotype is more a)

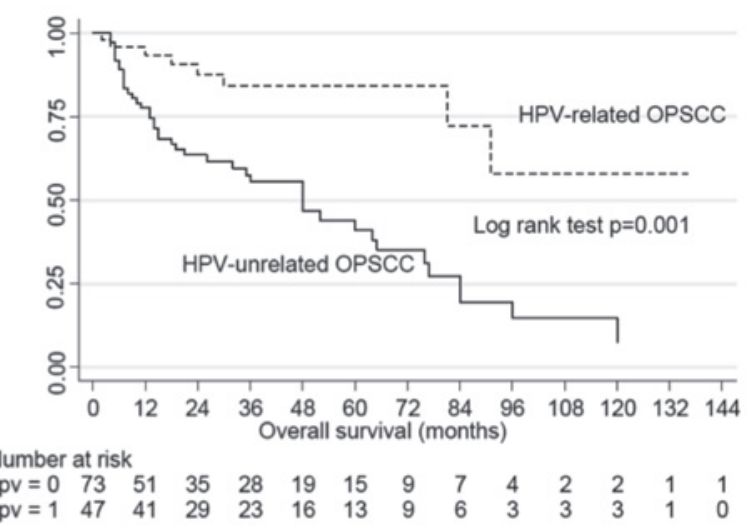

b)

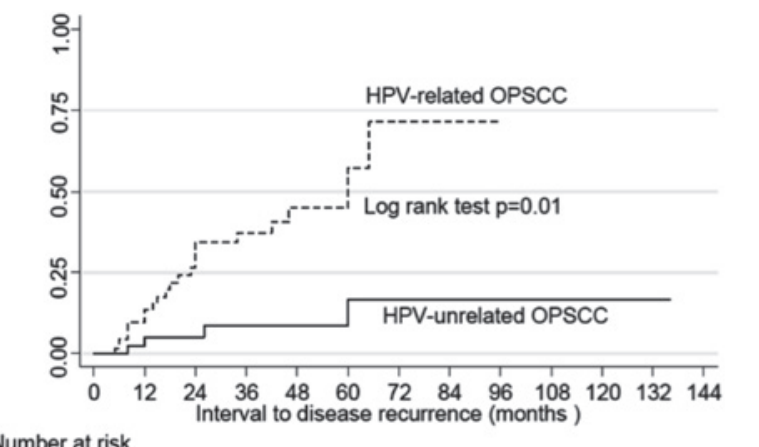

Number at risk

$\begin{array}{llllllllllllll}\mathrm{hpv}=0 & 74 & 47 & 29 & 21 & 11 & 9 & 4 & 4 & 3 & 1 & 1 & 1 & 1 \\ \mathrm{hpv}=1 & 46 & 39 & 28 & 21 & 14 & 11 & 6 & 4 & 2 & 2 & 2 & 1 & 0\end{array}$

Fig. 1. Overall survival and time to recurrence for HPV-related and unrelated OPSCC patients. 
strongly associated with HPV-related oncogenesis than its anatomical location. Garnaes et al. ${ }^{29}$ recently combined imaging and pathological parameters to classify tumour origin in a registry-derived OPSCC series form eastern Denmark, documenting a $2.7 \%$ yearly increase of tonsillar-based tumours in the years 2000-2010, which was explained with an increase of HPV-related cases (from $68 \%$ in 2000 to $82 \%$ in 2010). In our series, we similarly found a significant increase of HPV-related cases after 2010 among tumours with anatomical involvement of the tonsils, although defined by different criteria and also including palatine tonsils; this increase was associated with an increase of non-keratinising OPSCC. It is important to notice, however, that HPV status was the only significant prognostic predictor in multivariate analysis, while neither tumour topography nor morphology impacted the risk of recurrence or patient survival. The latter should not be used to pre-select cases to submit to HPV testing, but rather all OPSCC should be tested to provide patients with adequate care. From a pathogenic point of view, the relationship between HPV infection and squamous cell keratinisation remains a matter of study. The occurrence of typical keratinising OPSCC hosting oncogenic HPV infection observed in our and other series ${ }^{30}$ suggests that either HPV oncogenesis is not restricted to crypt epithelium and may as well involve the tonsillar surface, or that transformed crypt cells can undergo keratinisation (a phenomenon observed in ageing crypts).

In a present study, we confirmed in OPSCC, $70 \%$ of which were positive for HPV DNA, our previous observation of a high prevalence of HPV infection in tumour and oral cell samples of HNSCC patients ${ }^{15}$. The rate of HPV-DNA positive cases did not change over time, and is at least partially related to the high sensitivity of SPF10-LiPA amplification and genotyping platform. However, we observed that after 2010 oncogenic infections became more frequent and passenger HR infections, mostly sustained by HR-HPV non16 genotypes, were less common. We have no explanation for this epidemiological shift, considering that the methods of analysis were the same in the entire cohort and that tests on the older samples were repeated to confirm the original results. It is clear that the distribution of HPV genotypes within a population is influenced by several factors, including evolving sexual behaviours, migratory trends, and more recently vaccination campaigns, and thus changes over time ${ }^{31} 32$. The lack of recent epidemiological data on the evolution of HPV infection distribution in Italy, and on sexual attitudes of the study cohorts impairs an explanation of this trend. Although the majority of oncogenic infections could be attributed to HPV16, as widely reported, isolated non-HPV-16 oncogenic infections were responsible for $15 \%$ of OPSCC. A recent large international study reported a similar proportion (12\%) of non-HPV16 HR infections detected with SPF10LiPA in OPSCC ${ }^{6}$; in a comprehensive metaanalysis, their prevalence varied between $0.1 \%$ and $1.6 \%$ in OPSCC series from different geographical regions ${ }^{10}$; in both studies, however, the oncogenic role of non-HPV16 HR infections was not specified. The full extent of the involvement of these genotypes in OPSCC neoplastic transformation is still unclear. These observations support the use of broadspectrum genotyping tests, and of more than one DNA-based test to reduce the risk of false negative results.

Our study clearly suffers of several limitations, in particular the lack of information on how OPSCC prevalence has changed in our geographical area in the considered time interval. The impact of therapy on patient outcomes could not be fully evaluated because of the remarkable changes occurred in treatments offered to patients over the time covered by the study. Finally, the retrospective quality of the study prevented a complete analysis of risk factor exposure, including sexual behaviours, which would have proven useful to explain the high prevalence of HR passenger infections.

\section{Conclusions}

The results of the present single centre experience highlight the urge for extensive national registries to map the geographic distribution and time evolution of tumours associated with actionable risk factors, and for the collaboration of the scientific societies involved. In particular, the evaluation of the impact that HPV vaccination will have on the epidemiology of oropharyngeal cancer in the younger generations will require more accurate monitoring and classification of these cancers and their correlation with exposure data.

\section{Acknowledgements}

This work was supported by grants RC08017800/12, RC08053903/12 and RF-2011-02351315 from the Italian Health Ministry to the IRCCS Policlinico San Matteo Foundation, Pavia, G11961 from Associazione Italiana per la Ricerca sul Cancro (AIRC).

\section{Conflict of interest statement}

None declared.

\section{References}

International Agency for Research on Cancer (IARC). Monographs on the evaluation of carcinogenic risks to humans, in human papillomaviruses. Lyon, France: World Health Organization; 2007.

2 Gillison ML, D’Souza G, Westra W, et al. Distinct risk factor profiles for human papillomavirus type 16-positive and human papil- 
lomavirus type 16- negative head and neck cancers. J Natl Cancer Inst 2008;100:407-20.

3 Ang KK, Harris J, Wheeler R, et al. Human papillomavirus and survival of patients with oropharyngeal cancer. $\mathrm{N}$ Engl $\mathrm{J}$ Med 2010;363:24-35.

4 Chaturvedi AK, Anderson WF, Lortet-Tieulent J, et al. Worldwide trends in incidence rates for oral cavity and oropharyngeal cancers. J Clin Oncol 2013;31:4550-9.

5 Gillison M, Chaturvedi AK, Anderson WF, et al. Epidemiology of human-papillomavirus-positive head and neck carcinoma. J Clin Oncol 2015;33:3235-42.

6 Castellsagué X, Alemany L, Quer M, et al. HPV involvement in head and neck cancers: comprehensive assessment of biomarkers in 3680 patients. J Natl Cancer Inst 2016;108:djv403.

7 Chaturvedi AK, Engels EA, Pfeiffer RM, et al. Human papillomavirus and rising oropharyngeal cancer incidence in the United States. J Clin Oncol 2011;29:4294-301.

8 Psyrri A, Rampias T, Vermorken JB. The current and future impact of human papillomavirus on treatment of squamous cell carcinoma of the head and neck. Ann Oncol 2014;25:2101-15.

9 Bhatia A, Burtness B. Human papillomavirus-associated oropharyngeal cancer: defining risk groups and clinical trials. J Clin Oncol 2015;33:3243-50.

10 Ndiaye C, Mena M, Alemany L, et al. HPV DNA, E6/E7 mRNA, and p16INK4a detection in head and neck cancers: a systematic review and meta-analysis. Lancet Oncol 2014;15:1319-31. Erratum in: Lancet Oncol 2015;16:e262.

11 Licitra L, Perrone F, Bossi P, et al. High-risk human papillomavirus affects prognosis in patients with surgically treated oropharyngeal squamous cell carcinoma. J Clin Oncol 2006;24:5630-6.

12 Granata R, Miceli R, Orlandi E, et al. Tumor stage, human papillomavirus and smoking status affect the survival of patients with oropharyngeal cancer: an Italian validation study. Ann Oncol 2012;23:1832-7.

13 Bussu F, Sali M, Gallus R, et al. Human papillomavirus (HPV) infection in squamous cell carcinomas arising from the oropharynx: detection of HPV DNA and p16 immunohistochemistry as diagnostic and prognostic indicators - a pilot study. Int J Radiat Oncol Biol Phys 2014;89:1115-20.

14 Donà MG, Spriano G, Pichi B, et al. Human papillomavirus infection and p16 overexpression in oropharyngeal squamous cell carcinoma: a case series from 2010 to 2014. Future Microbiol 2015;10:1283-91.

15 Morbini P, Dal Bello B, Alberizzi P, et al. Oral HPV infection and persistence in patients with head and neck cancer. Oral Surg Oral Med Oral Pathol Oral Radiol 2013;116:474-8.

16 Morbini P, Alberizzi P, Tinelli C, et al. Identification of transcriptionally active $H P V$ infection in formalin-fixed, paraffin-embedded biopsies of oropharyngeal carcinoma. Hum Pathol 2015;46:681-9.

17 Edge SB, Byrd DR, Compton CC, et al. AJCC cancer staging manual. Seventh Edition. NY: Springer; 2010.
18 Smeets SJ, Hesselink AT, Speel EJ, et al. A novel algorithm for reliable detection of human papillomavirus in paraffin embedded head and neck cancer specimen. Int J Cancer 2007;121:2465-72.

19 Thavaraj S, Stokes A, Guerra E, et al. Evaluation of human papillomavirus testing for squamous cell carcinoma of the tonsil in clinical practice. J Clin Pathol 2011;64:308-12.

20 Grisar K, Dok R, Schoenaers J, et al. Differences in human papillomavirus-positive and-negative head and neck cancers in Belgium: an 8-year retrospective, comparative study. Oral Surg Oral Med Oral Pathol Oral Radiol 2016;12:456-60.

21 Melchers LJ, Mastik MF, Samaniego Cameron B, et al. Detection of $H P V$-associated oropharyngeal tumours in a 16-year cohort: more than meets the eye. Br J Cancer 2015;112:1349-57.

22 Westra WH. Detection of human papillomavirus (HPV) in clinical samples: evolving methods and strategies for the accurate determination of HPV status of head and neck carcinomas. Oral Oncol 2014;50:771-9.

23 Smith EM, Rubenstein LM, Haugen TH, et al. Complex etiology underlies risk and survival in head and neck cancer human papillomavirus, tobacco, and alcohol: a case for multifactor disease. $\mathrm{J}$ Oncol 2012:571862

24 Baboci L, Holzinger D, Boscolo-Rizzo P, et al. Low prevalence of HPV-driven head and neck squamous cell carcinoma in North-East Italy. Papillomavirus Res 2016;2:133-40.

25 Quabius ES, Haag J, Kühnel A, et al. Geographical and anatomical influences on human papillomavirus prevalence diversity in head and neck squamous cell carcinoma in Germany. Int J Oncol 2015;46:414-22.

26 Capocasa M, Anagnostou P, Bachis V, et al. Linguistic, geographic and genetic isolation: a collaborative study of Italian populations. $\mathrm{J}$ Anthropol Sci 2014;92:201-31.

27 O'Sullivan B, Lydiatt WM, Haughey $\mathrm{BH}$, et al. HPV-mediated (p16+) oropharyngeal cancer. In: AJCC cancer staging manual. Eighth Edition. NY: Springer; 2017.

28 Kim SH, Koo BS, Kang S, et al. HPV integration begins in the tonsillar crypt and leads to the alteration of p16, EGFR and c-myc during tumor formation. Int J Cancer 2007;120:1418-25.

29 Garnaes E, Kiss K, Andersen L, et al. Increasing incidence of base of tongue cancers from 2000 to 2010 due to HPV: the largest demographic study of 210 Danish patients. Br J Cancer 2015;113:131-4.

30 Cai C, Chernock RD, Pittman ME, et al. Keratinizing-type squamous cell carcinoma of the oropharynx: p16 overexpression is associated with positive high-risk HPV status and improved survival. Am J Surg Pathol 2014;38:809-15.

31 Dal Bello B, Spinillo A, Alberizzi P, et al. Time trends of human papillomavirus type distribution in italian women with cervical intraepithelial neoplasia (CIN). Gynecol Oncol 2009;115:262-6.

32 Bosch FX, Burchell AN, Schiffman M, et al. Epidemiology and natural history of human papillomavirus infections and type specific implications in cervical neoplasia. Vaccine 2008;26(Suppl 10):K1-16.

Received: August 16, 2017 - Accepted: November 27, 2017

How to cite this article: Morbini P, Alberizzi P, Ferrario G, et al. The evolving landscape of human papillomavirus-related oropharyngeal squamous cell carcinoma at a single institution in Northern Italy. Acta Otorhinolaryngol Ital 2019;39:9-17. https://doi. org/10.14639/0392-100X-1905

Address for correspondence: Patrizia Morbini, Department of Molecular Medicine, Unit of Pathology, via Forlanini 16, 27100 Pavia, Italy. Tel. +390382 501240. E-mail: patrizia.morbini@unipv.it 